\title{
LOS BARRIOS DE ELVIRA LINDO
}

\section{Carmen SERVÉN DÍEZ}

Universidad Autónoma de Madrid

\section{RESUMEN}

La actual teoría de la literatura procura superar la concepción del espacio como ámbito exclusivamente topográfico de la historia y aborda, desde diversos ángulos y con resultados dispares, el problema del espacio como aspecto crucial de la mímesis. La crítica ha mostrado ya que la tematización de ciertos espacios y su consiguiente valor simbólico se relacionan con las coordenadas socio-económicas e históricas en que se consolidan ciertas formas de vida y pensamiento, así como ciertos criterios estéticos. De ahí que algunos espacios bien diferenciados se conviertan en tópicos durante determinados periodos artísticos, y adquieran un valor simbólico concreto a través de la mirada de un autor particular. Tal ocurre con el barrio madrileño, que constituye una constante en la obra narrativa de Elvira Lindo y se erige además en síntoma de la realidad social contemporánea.

En las novelas de Lindo, el hombre y su paisaje se acompañan en el seno del barrio dibujando el mundo peculiar del Madrid posmoderno, en que la globalización y otros fenómenos modifican notoriamente el mosaico urbano: la yuxtaposición de razas, etnias, culturas y valores; la consideración de un centro histórico mítico y vacío, frente a los centros comerciales periféricos que cubren el ocio de la población; las enormes masas de inmigrantes que se instalan en zonas bien circunscritas, forjando así una peculiar forma de chinatown, como Lavapiés... Madrid ya no es una ciudad con una almendra central de ocio y comercio, sino una constelación de barrios peculiares en los que arraiga el apego del urbanita.

Lindo procura captar los «espacios diferenciales» de lo urbano; siempre consciente de que el espacio no es un vacío colmado o no de materiales, y de que el grado de centralidad es relevante. Su novelística es, entre otras muchas ofertas interpretativas de la realidad, un homenaje y una crónica posmoderna de los barrios de Madrid, especialmente de los barrios del extrarradio. No se entienda por ello que se trata de un conjunto narrativo reducido a la fotografía costumbrista; Lindo habla de desgarros 
interiores, de superación y crecimiento personal, de relación entre el interior y el exterior de las personas..., lo que desborda a todas luces la pintura de costumbres.

Palabras clave: Elvira Lindo, espacio narrativo, barrio, Madrid, posmodernidad

\section{ABSTRACT}

The current theory of literature seeks to overcome the conception of space as a Material context of the story and addresses, from different angles and with varying results, the problem of space as a crucial aspect of mimesis. Critics have already shown that the use of certain spaces grants them a symbolic value. This happens with the districts o Madrid which are a constant in the narrative works of Elvira Lindo and stand also a symptom of contemporary social reality.

In the novels of Lindo, globalization and other phenomena have notably modified the urban mosaic: the juxtaposition of races, ethnicities, cultures and values, the transformation of the city model into a polycentric scheme, the huge masses of immigrants who settle in well circumscribed areas, forging a peculiar form of Chinatown.... Madrid is no longer a city with a central core of leisure and commerce, but a constellation of distinctive neighborhoods that become the habitat of the urbanite.

Lindo seeks to capture the «differential spaces» of the urban, she is always aware that space is not a vacuum filled or not, and that the degree of centrality is relevant. Her novels are, among other deals interpretation of reality, a postmodern tribute and a chronicle of the neighborhoods of Madrid, especially in suburban neighborhoods. Do not understand why this is reduced to a narrative of traditional photography, the author speaks of interior tears, overcome, and personal growth, relationship between inside and outside of the people..., which overwhelms clearly the painting of manners. Key words: Elvira Lindo, narrative space, neighborhood, Madrid, postmodernism

La percepción del espacio se ejecuta desde presupuestos distintos y con distintos resultados a lo largo de la Historia del Arte. Entre los estudiosos de la Literatura, ya Claudio Guillén destacaba la capacidad configurativa del espacio que posee la mirada humana ${ }^{1}$, por su parte, Leonardo Romero Tobar avisaba que la elaboración artístico-plástica y literaria del espacio es un «elemento fundamental en la estructura de la obra literaria y logra su máxima potenciación en los textos de ambientación realista $»^{2}$. Ambos profesores contribuyen

1. «Es precisamente la mirada humana lo que convierte cierto espacio en paisaje», decía el profesor (Guillén, 1996: 67).

2. Romero Tobar desliza el punto de vista citado en un estudio dedicado a anotar la relación existente entre localización geográfica y cierta clase de empleo del espacio. Es decir: emprende un estudio vinculado a la consideración de que el espacio y su representación o configuración en la obra literaria pueden adquirir distintos aspectos y funciones. Análisis reciente de distintos textos acerca de Madrid sobre los que se proyectan estilo, 
pues a poner de relieve la importancia que adquiere en el arte la configuración del espacio, que consideran sometido a instancias intencionales y estilísticas.

La cuestión espacial ha cobrado así singular interés para la crítica literaria y es objeto de aproximaciones por parte de grupos de investigación diversos que procuran iluminarla en textos también variados: véase por ejemplo, el excelente volumen plural editado por Carmen Porrúa, que recoge los resultados obtenidos por un equipo de investigación atento a la copiosa bibliografía previa sobre la relación ciudad/literatura debida a autores como Lotman, Bachelard, Bajtin o Benjamin y, en consecuencia, busca nuevas formas de abordar la cuestión. El mencionado corpus teórico de partida insta precisamente a abandonar «la idea simplificadora del espacio-marco», para enfocar el problema desde otros ángulos: prisma ideológico, construcción referencial, configuración de personajes y situaciones... (Porrúa, 1999: 6). Como ya avisaba Vallés Calatrava cuatro años antes, los trabajos recientes sobre el espacio literario han procurado «superar su concepción como ámbito exclusivamente topográfico de la historia e incardinarlo en un funcionamiento textual más complejo» (1996: 1528). Y además, como quiere Garrido Domínguez (1996: 721), hay que contar con planteamientos como los de Bachelard y Durand, que «se interesan fundamentalmente por el significado del espacio a través de su conexión con arquetipos culturales y, en definitiva, antropológicos» (1996: 720).

Por su parte, R. Bourneuf y R. Ouellet anotaban que «las nociones de descripción y, más en general, espacio narrativo han sufrido numerosos avatares» a lo largo de la historia de la novela (1975: 129) y aseguraban que «la representación del espacio en la novela constituye uno de los aspectos concretos del problema crucial de la mímesis, del que se ocupan escritores, historiadores y críticos desde Platón y Aristóteles» (1975: 139). Además avisaban de que las fórmulas y efectos de la representación de lo espacial en un texto novelesco son variadísimas, desde la oferta de un mínimo de indicaciones geográficas, hasta la minuciosa descripción material o también la tematización del espacio (1975: 115 y ss.).

Precisamente, sabemos también que la tematización de ciertos espacios y su consiguiente valor simbólico, se relacionan con las coordenadas socioeconómicas e históricas en que se consolidan ciertas formas de vida y pensamiento, al igual que ciertos criterios estéticos. Así, por ejemplo, en un trabajo extraordinariamente atractivo, Lily Litvak ha mostrado la importante

peculiaridades personales e ideas estéticas de escritores diversos en momentos sucesivos de la historia de la literatura, es el revelador artículo de Rebeca Sanmartín Bastida. Los estudios sobre Madrid como espacio narrativo son numerosísimos; se hallarán al respecto muchas referencias bibliográficas actualizadas en el trabajo de Tudoras. 
presencia de cierta clase de espacios y de motivos ambientales concretos en la gran literatura del realismo: los grandes puertos, la maquinaria o el ferrocarril, irrumpen con fuerza en la literatura de fines del siglo XIX en España, en plena expansión industrial. La investigadora destaca especialmente la omnipresencia del tren, que constituye «el símbolo más expresivo de la colonización del paisaje por la industria en el siglo XIX» (Litvak, 1991: 181) ${ }^{3}$.

Pues bien, si ciertos elementos o espacios bien diferenciados constituyen tópicos en determinados periodos artísticos y adquieren un valor simbólico concreto a través de la mirada de un autor particular, el barrio constituye una constante en la obra narrativa de Elvira Lindo y se erige además en síntoma de la realidad social contemporánea. Es cierto que la autora ha afirmado en entrevista con Óscar López (2002: 52) que«igual que en las películas prefiero el plano medio, en la vida prefiero el ser humano al paisaje»; sin embargo, en sus novelas el hombre y su paisaje se acompañan en el seno del barrio dibujando el mundo peculiar de la España posmoderna. Con ello, se ha dicho, la autora se sitúa «a la cabeza de la novelística que rinde homenaje a los personajes anónimos de condición modesta» (G. Iturbe, 2005: 58).

El rastro autobiográfico está, desde luego, operando en los relatos de Lindo. Ella misma ha «repetido hasta la saciedad ${ }^{4}$ que no procede de familia obrera, pero sí de un barrio periférico: Moratalaz. Su padre era un alto ejecutivo y ella se atrevía a coger en ocasiones taxis para acudir a estudiar a la Facultad; pero en su mundo adolescente o juvenil convivió con familias de clase media y otras de posición inferior. La experiencia del barrio está bien arraigada en la biografía de Elvira Lindo.

Todo ello contribuye a situar a la autora en el vértice de la posmodernidad. Como avisa la geógrafa Emilia García Escalona, Madrid ha venido sufriendo a fines de siglo un «silencioso» proceso de cambio (2002: 173); el «mosaico urbano está cambiando sus teselas poco a poco» (2002: 174), y dada la inexorable globalización a que asistimos, «lo local o singular se convierte en una cualidad cada vez más apreciada» (García Escalona, 2002: 1745). Lindo recoge precisamente gran parte de los factores que permiten hablar de Madrid como urbe posmoderna: la yuxtaposición de razas, etnias, culturas y valores; la consideración de un centro histórico mítico y vacío, frente a los

3. El tren en la literatura ha sido objeto de atención por parte de otros investigadores; véase, por ejemplo, el artículo de González Herrán (1996). Evidentemente las artes plásticas de ese período también incluyen al tren en sus construcciones del espacio; recuérdense los cuadros de Darío Regoyos.

4. Son palabras de la escritora en su entrevista ya citada con Óscar López (2002: 54).

5. García Escalona (2002) sigue de cerca, según ella misma indica, a Pérez Sierra (2000). 
centros comerciales que cubren el ocio de la población; enormes masas de inmigrantes que se instalan en zonas como bolsas, zonas que constituyen una peculiar forma de chinatown, como, por ejemplo, Lavapiés. Madrid ya no es una ciudad con una almendra central de ocio y comercio, sino una constelación de barrios peculiares en los que arraiga el apego del urbanita.

La presencia del barrio y su proyección sobre la caracterización de los personajes y de la acción son elementos clave ya en la primera colección de relatos publicada en volumen por Elvira Lindo: Manolito Gafotas (1994). Este libro, que tuvo extraordinario éxito entre niños y adultos, ofrece en un volumen breves narraciones sobre un personaje que se había venido haciendo famoso a través de la radio desde los años ochenta ${ }^{6}$; su creadora, con una larga trayectoria en la redacción de programas radiofónicos diversos y capaz además de intervenir como actriz en ellos, redactaría después varios volúmenes más en torno a Manolito: Manolito Gafotas, Pobre Manolito, ¡Cómo molo!, Los trapos sucios, Manolito on the road y Yo y el imbécil. Como ha mostrado Salvador Oropesa (2003: 17), estos libros no son idénticos entre sí, sino que cada entrega de historias de Manolito se fragua en torno a matices distintos del personaje y su ambiente, aunque siempre se respeta la caracterización de los personajes y el entorno que fijaba el volumen inaugural (Oropesa, 2003: 17).

El comienzo absoluto de la serie de libros dedicada a Manolito Gafotas se abre con una presentación que el personaje central hace de sí mismo: «Me llamo Manolito García Moreno, pero si tú entras en mi barrio y le preguntas al primer tío que pase...» (9). Así, el nombre del personaje y el barrio, como entorno de referencia, resultan inseparables y definitorios desde un principio. La presencia del barrio es constante y se reitera una y otra vez con funciones sutilmente matizadas, pero siempre abocadas a ubicar escenas de ese carácter costumbrista del que ha hablado Santos Sanz Villanueva (2002). Desde la primera página del primer libro de la serie, Manolito aparece flanqueado por su mejor amigo, el Orejones, por sus padres y por un espacio bien determinado: «Carabanchel, que es mi barrio» (9; también en 16, 78, 105). La expresión «mi barrio» no se le cae de la boca al protagonista narrador $(74,78)$; y funciona como una proclamación de pertenencia.

La elección de un barrio madrileño periférico para ambientar las historias de Manolito es decisiva en lo que respecta al significado y al éxito de la serie. Se trata de un barrio suburbial de bloques en altura cuyas viviendas alcanzan en general precios moderados y cuyos habitantes son gentes modestas. Estos

6. En el programa «Mira la radio», de Radio Nacional, 1988; pasó luego a la SER, al programa «A vivir que son dos días» (Oropesa, 2003: 17). 
vecinos se han instalado en la capital no antes de la penúltima generación e integran el aluvión de inmigrantes que acuden a la gran urbe con el afán de mejorar sus condiciones de vida, pero traen expectativas y costumbres tradicionalmente rurales y familiares. Carabanchel es un barrio popular y, de esta forma, Manolito y su familia forman parte de un contingente humano bien perfilado en el imaginario cultural español.

El barrio, Carabanchel, es visto desde la óptica de Manolito, cuyas explicaciones sobre él están supeditadas a una anárquica lógica infantil que dota de color local a las historias. Dice por ejemplo: «En mi barrio, que es Carabanchel, hay de todo: hay una cárcel, autobuses, niños, presos, madres, drogadictos y panaderías...» (16). En enumeraciones como ésta los personajes propios del mundo infantil («niños», «madres») se yuxtaponen a un paisaje urbano convencional («autobuses», "panaderías») pero también a edificios y personajes propios de un centro urbano muy conflictivo o degradado («cárcel», «drogadictos»); todo ello configura la amalgama familiar a un niño del extrarradio más modesto.

El protagonista de estos textos, Manolito, ha sido ya objeto de rigurosos análisis socio-críticos: es un niño corriente, que «emplea un lenguaje mezcla de muchos acentos, murciano, andaluz y manchego» puesto que «trata de representar a todos los niños españoles», pero especialmente los del sur (Oropesa, 2003: 20). Sus amigos también son paradigmáticos, pues constituyen ejemplares característicos de la clase media baja (Oropesa, 2003: 21). Todo ello viene a corroborar la intención autorial de lograr un retrato costumbrista de una barriada madrileña de fin del siglo XX: los lances, episodios, ambientes, personajes, reacciones..., forman parte de la vida cotidiana en la periferia de Madrid a la que se ha añadido una pizca de lo grotesco y se ha restado todo verdadero asomo de tragedia. Veamos un par de ejemplos. El «chulito de mi barrio» es en la serie Yihad ${ }^{7}$, un chico agresivo y fuerte cuyo nombre revela procedencia extranjera, pero en ningún momento Yihad o su abuelo, que es amigo del abuelo del propio Manolito, se revelan extraños a la vida habitual del barrio. Yihad, como toda la pandilla de Manolito, visita a la psicóloga del colegio, porque la maestra sospecha que todos ellos van a «acabar siendo unos delincuentes» (29). Sin embargo, desde la mirada ingenua del protagonista narrador, estos chicuelos de barrio no son distintos a los demás niños. La diferencia entre Yihad y el resto existe exclusivamente en el plano del arrojo y

7. El matón de barrio es una figura tópica que reaparece en obras posteriores de Elvira Lindo; En El otro barrio hallamos a Valentín, que se ríe de los más débiles y propala la historia de «sus insignificantes hazañas de héroe de barrio» (106). 
la fuerza física; pero cualquier atisbo de conflicto intercultural está descartado en la mirada de Manolito.

Con idéntica naturalidad se relata el atraco que sufre el abuelo de Manolito: «Viene un tío de tantos que se ven por mi barrio y le dice que le dé doscientas pesetas» (55); como el abuelo se niega, «va el tío y saca una navaja de grandes dimensiones y nos amenaza» (55). Pero el lance toma caminos insospechados, pues la navaja procede del pueblo del abuelo, éste pregunta al atracador sobre su procedencia, y cuando éste reconoce que es hijo de una señora de aquel lugar, el abuelo lo amenaza con revelar a la madre las andanzas del ladrón. De esta forma el atracador termina devolviendo el dinero sustraído y además entregando la navaja a sus víctimas (57-58). El paisaje familiar y el color local tiñen de cotidianidad inofensiva lo que en otra clase de ficción podría cobrar aire truculento. Los ecos del esperpento afín a otras ficciones del mismo periodo se perciben en esta naturalización de la transgresión, que se despoja de lo siniestro para ofrecerse llena de colorido y gracia, tal como sucede en las películas de Pedro Almodóvar.

Además, el barrio constituye el marco de todas las iniciativas y celebraciones en que participa Manolito: los eventos escolares, los aniversarios y fiestas... El barrio es el territorio en que Manolito y sus amigos quieren triunfar. Cuando se disfrazan, siguiendo una línea pacifista impuesta por los adultos, los chicos piensan: «íbamos a machacar a todos los niños de todos los colegios del barrio con nuestros trajes de palomas de la paz» (108); mientras tanto, el hermano pequeño de Manolito también pensaba destacar en espacio igualmente acotado: lucía encantado un disfraz «convencido de que era el más bonito del barrio» (117). La actitud de todos estos niños revela las contradicciones propias y ajenas. Así, el apego y la crítica al barrio se entreveran inconscientemente en el discurso de Manolito, que explica por ejemplo: «iban a retransmitir el festival por Radio Carabanchel, que es una radio que se hace en mi barrio y que, como no tienen dinero para micrófonos, mi abuelo dice que hacen los programas por el viejo sistema indio de abrir la ventana y hablar a gritos» (112). Y el barrio es la comunidad cuya voz marca la regla: «en eso está de acuerdo todo Carabanchel» (130), lo que implica una verdad irrebatible. Carabanchel es el centro del «mundo mundial» según la percepción de Manolito, con su meteorología peculiar (136) y donde todas las familias reciben el verano con hábitos parecidos (137).

El éxito del Manolito inicial, y el gran eco de toda la serie, sin duda animaron a Elvira Lindo a transitar los caminos del relato impreso. Y más adelante, empezó a ofrecer novelas de mediana extensión y no orientadas al público infantil. La primera de ellas se vincula al barrio ya desde el título: El otro 
barrio (1998). Es una historia en que la concatenación inverosímil de casualidades convierte a un adolescente en sospechoso de varios asesinatos. En esta novela hallamos de nuevo como marco de referencia un barrio madrileño del extrarradio popular: Vallecas. Y el protagonista otra vez es un chico, ahora un adolescente de quince años, «que por no se sabe qué extrañas razones acabó con la vida de dos personas y un perro $»^{8}$.

En la cadena de azares y malentendidos que constituyen el punto de partida de la historia narrada, el barrio constituye un marco de referencia y un espacio cuyas características se proyectan sobre la acción y sus resultados. Así, cuando el chico, Ramón Fortuna, procura escapar del escenario de sus azares y desgracias, su aparente culpabilidad se refuerza ante los demás cuando la voz narrativa explica:

Corrió frenéticamente. Probablemente a nadie le extrañó aquella carrera. Cuando un chico corre de esa manera o bien ha robado un bolso o bien pierde el autobús o ha tomado algo. Ninguna de las tres cosas son extrañas en el barrio (50).

El abogado defensor de Ramón Fortuna es un hombre joven que se siente vinculado a su cliente por lazos anudados antaño entre sus dos familias, residentes en el mismo barrio: Marcelo, el abogado, piensa al respecto lo siguiente:

La cosa es que él también era de aquel barrio, bueno, mejor sería decir que había sido, porque todo aquello le parecía de una vida anterior a la que no le apetecía demasiado acercarse. Nunca sintió ese sello del barrio que dicen tener algunos vallecanos, al contrario, desde muy joven se encontró ajeno y en cuanto pudo se marchó de allí, no sólo físicamente, sino también de la clase social en que se había criado (55).

Marcelo ha prosperado y ha escapado del barrio original, y en su mente contrasta la vida pasada en el barrio periférico con la del presente en el barrio céntrico:

El olor de la coliflor recocida que inundaba la escalera de su casa; los domingos por la tarde en el barrio, sin un duro, estudiando en un cuarto desde el que se oía la televisión de sus padres, la radio del de al lado, los gritos del de arriba, y los polvos del de más allá, y la vergüenza por ser un chaval formal, el que quiere hacer carrera, el que no se droga. Cada cosa que él había conseguido había sido un paso para alejarse de aquellos tiempos; cada cosa que poseía era un anclaje más en su vida presente: una mujer preciosa, del barrio de Chamberí, del centro; una casita adosada en una urbanización de las afueras. No había vuelta atrás (56).

8. Un aspecto de esta novela que merece atención es el simbolismo onomástico: el desgraciado joven víctima del azar y acusado de asesinato múltiple se llama Ramón Fortuna; el matón de barrio es Valentín... 
Marcelo se resiste a regresar al barrio donde transcurrió su infancia: «no hay nada que me una a mi barrio», explica (100). Y ese barrio es, también a ojos de otros personajes, símbolo de una forma de vida estrecha y de una clase social que se desea abandonar. La madre de Ramón, Gloria, está decidida a sacar a su hijo del atolladero, de ahí que tome dos decisiones simultáneas y radicales: confesar a Ramón Fortuna que ella es su verdadera madre biológica, y sacar al chico del barrio: «No quiero que vuelva a un lugar que le es tan ingrato. Buscaré la forma de que viva en otro barrio» (121).

Por fin, el título de esta novela cobra doble sentido a la vista del párrafo final, pues en él Marcelo evoca a su padre, su niñez, su familia y el pasado; se siente próximo a Ramón Fortuna, y acepta las voces, «los ecos que nos llegan desde el otro barrio» (174): Vallecas y «el más allá» simultáneamente.

Algo más inesperado que la muerte (2002) ofrece de nuevo una clase de conflicto en que lo territorial es pertinente, aunque en este caso las tensiones de fondo son no sólo social de carácter social sino también sexual. Las rivalidades del mundo intelectual, la posición lograda gracias al matrimonio por la joven esposa de un escritor, la naturalidad, la independencia de criterio y el aplomo con que se comporta la criada y la revelación del conflicto, se despliegan ante el lector mientras un taxi se desplaza entre los dos polos geográficosociales de la novela. En un extremo, Eulalia que, gracias a su matrimonio con Samuel, forma parte de la crema intelectual madrileña, ubicada en el barrio de Salamanca y asidua al círculo de Bellas Artes y al Teatro Real; en el otro, Tere, la asistenta doméstica residente en San Blas ${ }^{9}$, un barrio popular que forma parte de ese conjunto urbano lleno de vida que son los barrios madrileños del extrarradio.

Al comenzar la novela, Eulalia recibe una llamada telefónica de su asistenta mientras se está preparando para ofrecer en su casa, dentro de pocas horas, una cena con dos camareros y varios importantes invitados; Tere interrumpe los quehaceres de Eulalia desde un barrio lejano. Reclama con insistencia a su señora, que acuda a verla, que su presencia es imprescindible (57). Eulalia sospecha incluso si no se habrá producido algún pequeño robo doméstico que Tere desearía ahora confesar.

Desde el inicio de la novela se contraponen dos figuras de mujer, una central, otra lejana, de distintas clases sociales, la señora del barrio de Salamanca, la asistenta doméstica de San Blas, y en ambas mujeres hay un rastro autobiográfico de la propia autora. Tere es una joven habitante de un barrio periférico popular, como lo fue Lindo; Eulalia, como la autora, ha vivido experiencias

9. Que la pija Eulalia confunde con el barrio de la Concepción en p. 53.

Anales, 24, 2012, pp. 351-367 
laborales ligadas a la radio (62). La aparente diferencia social y temperamental entre las dos mujeres de ficción, se diluirá paulatinamente a través de la novela. Veremos que ambas son de procedencia modesta y que ambas se las ingenian para progresar por medio de su buen palmito.

A partir del pasaje en que se introduce el barrio de Pacífico en la obra como lugar de origen de Eulalia, se despliega el difícil pasado de ésta ( 78 y ss); durante más de un centenar de páginas ${ }^{10}$, se van a mostrar los antecedentes y derivas en que se forja la personalidad de Eulalia: ambiciosa y pija, casada con un prestigioso y anciano escritor, y adúltera con un amante cuya inferior posición social es su principal defecto.

La segunda parte de la novela ${ }^{11}$ desarrolla la figura de Tere, cuya perspectiva personal sobre los hechos de la ficción constituye ahora el hilo del relato. Así, averiguamos cómo Tere cayó en brazos del señor de la casa que limpiaba, y conocemos el pasado de la joven:

Cuando el abuelo medio paralítico se fue a vivir a su casa porque ya no podía valerse por sí solo, la niña aceptó sus aproximaciones, que fueron al principio supuestamente casuales y luego premeditadas, como el resultado de la maldición que llevaba tantos meses torturándole el pensamiento, y a pesar del dolor y del terrible secreto, casi llegó a sentirse aliviada por saber exactamente en qué consistía la materialización de la amenaza (235).

Endurecida y solitaria tras sufrir abusos sexuales durante su infancia, Tere sueña con un hogar propio, un piso exterior en un barrio joven:

una casa con todas las ventanas a la calle, que entre luz por todas partes, y no el patio éste, que tengo que oler la coliflor que hace la de abajo y se me pega el tufo a la ropa tendida, un piso cerca de mi hermana, en Las Rosas... (255).

Tras presentar y desarrollar sucesivamente las dos figuras de mujer que polarizan la acción de este relato, el viaje en taxi de Eulalia, que ha venido recorriendo la enorme distancia urbana y social existente entre el barrio de Salamanca y el de San Blas, y que ha dado lugar a un largo recorrido narrativo por los pasados biográficos de las dos protagonistas, concluye y la señora llega frente al portal de la criada; el nuevo capítulo se abre cuando Eulalia «Ya esta aquí. Ha llamado al telefonillo» (258).

Es decir: el punto de vista narrativo se ha desplazado desde un «aquí» de Eulalia, que focalizaba inicialmente el relato y caminaba por un barrio céntrico y acomodado, hasta un «aquí» periférico y ligado a la figura de Tere. El encuentro entre ambas mujeres se produce en San Blas, y asistiremos a la

10. Casi la mitad de la extensión total de la novela, hasta página 226.

11. Desde página 227. 
estupefacción de Eulalia cuando comprenda que su marido la ha engañado de forma habitual con la asistenta (268), y a su enorme estupor cuando se hace cargo de que él acaba de morir en casa de ésta (270-71) durante una cita erótica. El juego de malentendidos que se suceden en la conversación entre ama y criada constituye una radiografía esperpéntica de las diferencias sociales en el Madrid de entresiglos. Y la distancia social se mide por la separación entre distintos barrios urbanos, que viene subrayada y a la vez cuestionada en pasajes como el siguiente:

La señora me dijo un día que la casa no funcionaría si no fuera por mí. Me lo dijo un domingo que se estropeó la caldera y me pidió que fuera desde mi barrio (San Blas), hasta el suyo (Alfonso XII) y fui y en un momento la dejé lista, funcionando. Luego ya no me lo ha vuelto a decir, pero no me hace falta que me regale el oído porque yo lo sé (272).

La tercera parte del relato, cuyo título es el de la novela -«Algo más inesperado que la muerte»- todavía depara mayores y más peliagudas sorpresas a Eulalia, sobre la que de nuevo se focaliza el relato, y al lector: Eulalia recorre Madrid con su chófer, camino de un homenaje que se va a tributar a su difunto marido en el barrio de las Rosas, un joven barrio de la periferia. En el acto-homenaje, la viuda ha de entregar un pequeño premio literario. Ante su asombro, Tere es la ganadora, y ha acudido acompañada de un chicuelo: el hijo póstumo de Samuel, el gran escritor fallecido.

Eulalia que, según venimos a saber, había comprado el silencio de Tere y que no contaba con la existencia del vástago, se da cuenta de que nunca acabará de pagar:

«Echa a andar hacia el coche. Le falta el aire [...] no habrá manera de librarse de ella, no habrá manera...» (314)

La novela y la geografía madrileña se han completado. Los barrios han funcionado como constelación de lugares de referencia personal repletos de connotaciones. Y los grupos humanos y sociales se han venido identificando con actividades, experiencias y locales emblemáticos en la historia del Madrid reciente ${ }^{12}$.

12. Con breve trazo se evoca, por ejemplo, el Madrid de los años sesenta del siglo XX, cuya datación se ofrece en p. 78, y cuya forma de ocio nocturno se dibuja poco antes (p. 77): «Todas aquellas mujeres que visitaban las salas de fiestas - boîtes donde actuaban los malos humoristas o los cantantes demodé - acompañadas de sus maridos pero que por su manera de vestir, de pintarse, de arreglarse el pelo, largo y un poco cardado en la parte de atrás, siempre daban la impresión de estar esperando una oportunidad más jugosa. A veces eran actrices de varietés, que después de la función se tomaban una copa, o gogós que animaban la pista, también había locutoras de televisión, de las de entonces, que sólo servían para anunciar la programación, cantantes sin mucho éxito, 
Una palabra tuya, aparecida en 2005, trata, una vez más, de personas corrientes que recorren los barrios de Madrid. La protagonista, Rosario, pertenece a una familia venida a menos; su voz conduce el relato y va mostrando las relaciones y experiencias que vive esta mujer contradictoria, arisca y vulnerable. Uno de los factores que juega un importante papel en esta novela es la evidente distancia entre las aspiraciones y las posibilidades que se ofrecen a los personajes. Para sobrevivir, Rosario ha de desempeñar un trabajo que disgustaría mucho a su madre por considerarlo un desdoro: barrendera. Así que Rosario ocupa ese puesto, pero lo oculta, asegurando que está destinada a una labor administrativa de oficina.

Ese trabajo clandestino, inconfesado en el entorno familiar y social, implica un permanente transitar por calles y parques de la geografía urbana madrileña. La ciudad se presenta como una retícula cuyos espacios son relativamente independientes o distintos entre sí, de tal modo que el carácter peculiar de esos espacios contribuye a fijar el sentido de cada paso de los personajes. Así, en un determinado momento explica Rosario que «limpiar la calle a la vista de todo el mundo» «es un palo» (34), confesando lo siguiente: «Me llega a tocar mi barrio en el reparto y yo no acepto el puesto, eso tenlo por seguro. Pero como me salió el barrio de Pacífico, me dije, esto para mi madre es como la China» (34).

La lejanía psicológica que así se establece entre dos barrios de Madrid es enorme. Y eso es lo que cuenta. El Madrid que se dibuja en esta novela no se acompaña de una descripción de barrio alguno, sino que es avalado por una imagen mental de distintas zonas de la capital, cuyo valor moral, material, práctico, social..., juega un papel en la historia. Los jardines del Matadero (135), Ventas (197), el Tanatorio (198), la calle Toledo (231), Mira el Río Baja (232)..., son mencionados como parajes ligados a los personajes. Tal como observa Rosario, la protagonista-narradora, «Parece que a cada persona le atribuimos un paisaje, ese donde nosotros la hemos conocido»... (231).

La contribución de ciertos sectores de la geografía madrileña a la caracterización de los personajes y de la acción es evidente en esta obra. Y asoma además una percepción muy interesante del paisaje urbano, un paisaje en que ciertas figuras pierden su carácter individual y humano a ojos del transeúnte, y quedan camufladas en el entorno; me refiero a la presencia de gentes uniformadas que sirven al sistema urbano y que los viandantes asumen como elementos del moblaje municipal:

o simplemente señoras casadas que conectaban con ese mundo por su amor a la juerga sin más». 
[...] en esta vida nunca estás a salvo. Me acuerdo de que un día se me cruzó una de las amigas viudas de mi madre. [...] La vi venir cruzando la calle hacia mí y pensé, joder, joder, es que no me lo puedo creer, otra vez esta tía, será posible [...] Se acercaba hacia donde yo estaba, paralizada, apoyada en el cepillo. Hubiera jurado que me estaba mirando, porque tenía la cara del que va, pero cuál no sería mi sorpresa cuando veo que la mirada de la tía me traspasa, sigue andando, y me deja atrás. No me había reconocido. Se ve que ni se le pasó por la cabeza que aquella barrendera que había dentro de un traje verde fosforescente y que tenía un cepillo en la mano era la hija de su vecina... (35).

Las tensiones, frustraciones y pesares que son objeto de esta novela se derivan a menudo de insatisfacciones sociales o relacionales. Tanto es así, que se ha hablado de «esperpento»y de «retrato social» de enorme precisión (G. Iturbe, 2005: 58); pero el sentido de la obra cobra su verdadera dimensión cuando nos damos cuenta de que las figuras humanas que la pueblan no sólo son anónimas, gente corriente ${ }^{13}$, sino además gentes invisibles en el paisaje urbano. Un paisaje del que estos personajes humildes disfrutan a deshora y en secreto:

Ya era la segunda primavera que estaba barriendo, y la verdad es que, con el tiempo uno se acomoda y empieza a distinguir lo malo de lo menos malo, y entonces lo menos malo parece maravilloso, y había mañanas como aquella, mañanas en las que aún no lucía la luz del día, pero el negro de la noche ya se había roto, en que daba gusto andar por la calle. Podíamos haber tomado el autobús, pero a mí me gustaba bajar la cuesta con las manos en los bolsillos, sin abrigo, sin bolso, sin nada más que el spray autodefensivo en la mochila... (133).

La primavera, esa primavera, me proporcionó un estado de ánimo muy extraño: por un lado estaba feliz, porque el frío cabrón se había terminado, y ya se sabe, amanece antes, y todo tiene un olor distinto; también es verdad que me había cambiado de zona y esa primavera yo estaba destinada a los jardines del Matadero. Comprendo que a mucha gente le pueda parecer una tontería, pero cuando llevas vaciando las mismas papeleras de una misma calle durante un año, el hecho de andar entre los árboles y los bancos de un parque te cambia la vida. (135).

La interioridad del personaje, que da voz al relato, y la forma en que se cree percibido por los demás, contrastan y se entreveran a lo largo de la novela. De nuevo, el conflicto narrado gira en torno a una sensibilidad personal cuyos puntos de referencia se ligan a distintos sectores del espacio urbano.

Para terminar, conviene tener a la vista Lo que me queda por vivir (2010), una novela de aprendizaje que muestra el difícil despegue de una joven

13. Antonio G. Iturbe (2005: 60), considera que esta novela de la autora vuelve sobre las «vidas corrientes de personas anónimas»; algo parecido puede hoy leerse en la página web oficial de Elvira Lindo (http://www.elviralindo.com/publicaciones.html). 
suburbial. La protagonista es una figura juvenil «de época» (12), «con el pelo panocha, vestidito pop, mallas, cejas negras y rotundas y labios pintados de rojo» (13); pero, además, es madre. A lo largo del relato, el apego y el gregarismo (51) que le inspiran los paisajes de la adolescencia -esa «placilla nada memorable de mi barrio en que habían vivido tanto la familia de mi marido como la mía cuando llegamos a Madrid»- serán trabajosamente superados para bascular hacia el gozo de la maternidad. No falta, claro está tratándose de un relato de Lindo, la referencia a la oralidad del barrio ${ }^{14}$ : la voz narrativa, que es la de la protagonista, caracteriza personajes y ambiente en cierto pasaje haciendo referencia a ese «acento de barrio de Madrid que para mí era la norma» (52). Es notorio que la figura central de esta novela posee características comunes con Lindo, ya que «poseía desde niña un don especial para captar las diferencias del habla [...] Era el rasgo humano que se me presentaba primero y con más nitidez...» (105).

Un elemento que no hemos visto operar en primer plano a lo largo de las novelas anteriores, se adelanta en las páginas de esta obra: la evocación de un mundo rural que se asocia a experiencias infantiles de regreso (138) y que da lugar a la descripción de espacios íntimos rememorados, espacios en que familiares de habla sentenciosa y dormitorios austeros, pero llenos de dignidad, determinan una forma de vida y de intervención en la historia narrada (108). Estos espacios que constituyen un paréntesis consolador alejado del tráfago y los conflictos vividos en Madrid.

De acuerdo con todo lo anotado más arriba, la narrativa de Elvira Lindo está estrechamente ligada a Madrid, sus barrios, sus paisajes, sus costumbres, sus tipos... Los barrios de esta ciudad juegan un importante papel, no sólo como marco de la acción, sino como determinantes y caracterizadores de la misma. Lindo escribe «Lavapiés», o «Pacífico», o «Vallecas», y está desgranando nombres de la geografía madrileña, sí, pero también deslizando enormes bolsas de significados connotativos que dan sentido al relato. La percepción psico-social del barrio en cuestión no acompaña, sino que condiciona,

14. El dominio del lenguaje coloquial es patente en todos los textos de Elvira Lindo. A ello se han referido entrevistadores como G. Iturbe (2005: 60), o estudiosos que han profundizado en los recursos técnicos del registro familiar, como Luisa Chierichetti. La propia autora, en entrevista para El País citada por Chierichetti (2006: 48-9), revela que busca el efecto de coloquialismo con harto trabajo; el entrevistador pregunta:» ¿No te preocupa escribir de forma tan corriente, tan de mesa camilla? ¿No tienes miedo que te llamen la Terelu de la escritura?»; y la autora responde: «Pues, la verdad, me parecería una falta de respeto, porque a mí escribir con naturalidad me cuesta bastante trabajo. A lo mejor es que tú lo consideras muy fácil. En ese caso, hazlo tú también, si es tan fácil, supongo que podrá hacerlo cualquiera» 
la evolución del conflicto narrado. Y esa percepción no descansa sobre una minuciosa descripción material de la geografía urbana, sino sobre detalles vivenciales que asoman y funcionan como referencias espacio-estructurales.

Hoy se afirma que el fenómeno urbano escapa a descripciones fenomenológicas o empíricas, que eluden la verdadera dimensión del problema; preguntas cruciales a la hora de iluminar la verdadera dimensión del asunto serían, por ejemplo, las relacionadas con las nociones de «centro»y «centralidad» (Lefebvre, 1976: 55). El fenómeno urbano como realidad global que afecta al conjunto de la práctica social (Lefebvre, 1976: 56), así como la negativa a una conceptualización del espacio consistente en imaginar «un vacío homogéneo en que se colocan objetos, individuos, máquinas, locales industriales, canales y redes de distribución...etc.» (Lefebvre, 1976: 56), cimentan una sensibilidad que pretende captar los «espacios diferenciales» de lo urbano. Es, precisamente, en esa línea de indagación donde se sitúa la narrativa de Elvira Lindo, siempre consciente de que el espacio no es un vacío colmado o no de materiales, y de que el grado de centralidad es relevante.

La novelística de Elvira Lindo es, entre otras muchas ofertas interpretativas de la realidad, un homenaje y una crónica posmoderna de los barrios de Madrid, especialmente de los barrios periféricos. No se entienda por ello que se trata de un conjunto narrativo reducido a la fotografía costumbrista; Lindo habla de desgarros interiores, de superación y crecimiento personal, de relación entre el interior y el exterior de las personas..., lo que desborda a todas luces la pintura de costumbres. El presente trabajo no se dirige a delimitar o agotar interpretaciones legítimas de la obra de Lindo, sino a mostrar una de las líneas de validación canónica de ese conjunto novelístico que, hasta ahora, ha suscitado, a mi juicio, escasos análisis críticos.

\section{BIBLIOGRAFÍA}

BOURneuf, R. y R. Ouellet (1972), La novela, Barcelona, Ariel, 1975.

ChiERICHETTI, Luisa, «Los artículos «conflictivos» de Elvira Lindo», en Antonella Cancellier, Maria Caterina Ruta, Laura Silvestri (coords.): Scrittura e conflitto: Actas del XXI Congreso Aispi, Catania-Ragusa 16-18 mayo, Vol. 2, 2006, pp. 47-60 y en http://cvc.cervantes.es/literatura/aispi/pdf/20/II_04.pdf

G. ITURBE, Antonio, «Elvira Lindo se pone seria», en Qué leer, abril de 2005, pp. 58-63.

GARCía ESCALONA, Emilia, «Madrid más allá de la modernidad», Revista de filología románica, Extra 3, dedicado a: Historia y poética de la ciudad. Estudios sobre las ciudades de la Península Ibérica, 2002, pp. 173-187. 
GARRIDO DOMíngueZ, Antonio, «El espacio en la ficción narrativa», en José María Pozuelo Yvancos y Francisco Vicente Gómez (eds.): Mundos de ficción. Actas del VI Congreso Internacional de la Asociación Española de Semiótica, Investigaciones semióticas, VI, Murcia, Universidad de Murcia, 1996, pp. 719-727..

GonZÁlez Herrán, José Manuel, «Trenes en el paisaje (1872-1901). Pérez Galdós, Ortega Munilla, Pardo Bazán, Pereda, Zola, Alas», en Darío Villanueva y Fernando Cabo Aseguinolaza (eds.), Paisaje, juego y multilingüismo. Actas el X Simposio de la Sociedad Española de Literatura General y Comparada, vol. I, Santiago de Compostela, Servicio de publicaciones de la Universidad de Santiago de Compostela, 1996, pp. 345-358.

GUILLÉN, Claudio, «El hombre invisible: paisaje y literatura en el siglo XIX», en Darío Villanueva y Fernando Cabo Aseguinolaza (eds.), Paisaje, juego y multilingüismo. Actas el X Simposio de la Sociedad Española de Literatura General y Comparada, vol. I, Santiago de Compostela, Servicio de publicaciones de la Universidad de Santiago de Compostela, 1996, pp. 67-84.

LEFEBVRE, Henri (1972), La revolución urbana, Madrid, Alianza, 1976.

Lindo, Elvira, Manolito Gafotas, Madrid, Alfaguara, 1994.

Lindo, Elvira (1998), El otro barrio, Madrid, Santillana, 2006.

LiNDO, Elvira (2002), Algo más inesperado que la muerte, Madrid, Santillana, 2006.

LiNDO, Elvira (2005), Una palabra tuya, Barcelona, Seix Barral, 2008.

LiNDO, Elvira, Lo que me queda por vivir, Barcelona, Seix Barral, 2010.

LITVAK, Lily, El tiempo de los trenes: el paisaje español en el arte y la literatura del realismo: (1849-1918), Barcelona: Ediciones del Serbal, 1991.

LÓPEZ, Óscar, «Entrevista a Elvira Lindo», Qué leer, 70 (2002), pp. 50-54.

OROPESA, Salvador, «La nueva familia española finisecular: Los García Moreno de la serie Manolito Gafotas» de Elvira Lindo, en Hispania, 86, 1 (2003), pp. 17-25

PÉreZ Sierra, Carmen, «Contactos y cambios culturales en la Era Global», en Lecturas geográficas. Homenaje a José Estébanez Álvarez, Madrid, Ed. Complutense, 200, pp. 581-591.

PorRúA, Carmen (ed.), Lugares: estudios sobre el espacio literario, Buenos Aires, Universidad de Buenos Aires, 1999.

ROMERO TOBAR, Leonardo, «Madrid y el uso del espacio en la literatura española de la posguerra», Anales del Instituto de Estudios Madrileños, 4 (1969), pp. 381-389.

SANMARTÍN BASTIDA, Rebeca, «La reescritura de Madrid: de Mesonero Romanos a Ramón Gómez de la Serna», en AnMal Electrónica 23 (2007).

Sanz Villanueva, Santos, reseña de Elvira Lindo, Algo más inesperado que la muerte, en El cultural, 26 de septiembre de 2002. http://www.elcultural.es/ version_papel/LETRAS/5467/Algo_mas_inesperado_que_la_muerte 
TUDORAS, Laura Eugenia, La configuración de la imagen de la gran Ciudad en la literatura postmoderna, 2004. (Tesis Doctoral dir. por la dra. E. Popeanga Chelaru), Madrid. http://www.ucm.es/BUCM/tesis/fll/ucm-t27819.pdf

VAllÉS CALATRAVA, José R., «Ficción y espacio narrativo. Organización y funcionamiento del espacio en La ciudad de los prodigios de Eduardo Mendoza», en José María Pozuelo Yvancos y Francisco Vicente Gómez (eds.), Mundos de ficción. Actas del VI Congreso Internacional de la Asociación Española de Semiótica, Investigaciones semióticas, VI, Murcia, Universidad de Murcia, 1996, pp. 1527-1534.

Fecha de recepción: 07-11-2011

Fecha de aceptación: 15-5-2011 